ARTIFICIAL SATELLITES, Vol. 50, No. 4 - 2015

DOI: 10.1515/arsa-2015-0016

\title{
ACCURACY ASSESSMENT STUDY OF UNB3M NEUTRAL ATMOSPHERE MODEL FOR GLOBAL TROPOSPHERIC DELAY MITIGATION
}

\author{
Ashraf Farah \\ Associate Professor, College of Engineering, Aswan University, Aswan, Egypt. \\ ashraf_farah@aswu.edu.eg
}

\begin{abstract}
Tropospheric delay is the second major source of error after the ionospheric delay for satellite navigation systems. The transmitted signal could face a delay caused by the troposphere of over $2 \mathrm{~m}$ at zenith and $20 \mathrm{~m}$ at lower satellite elevation angles of 10 degrees and below. Positioning errors of $10 \mathrm{~m}$ or greater can result from the inaccurate mitigation of the tropospheric delay. Many techniques are available for tropospheric delay mitigation consisting of surface meteorological models and global empirical models. Surface meteorological models need surface meteorological data to give high accuracy mitigation while the global empirical models need not. Several hybrid neutral atmosphere delay models have been developed by (University of New Brunswick, Canada) UNB researchers over the past decade or so. The most widely applicable current version is UNB3m, which uses the Saastamoinen zenith delays, Niell mapping functions, and a look-up table with annual mean and amplitude for temperature, pressure, and water vapour pressure varying with respect to latitude and height. This paper presents an assessment study of the behaviour of the UNB3m model compared with highly accurate IGS-tropospheric estimation for three different (latitude/height) IGS stations. The study was performed over four nonconsecutive weeks on different seasons over one year (October 2014 to July 2015). It can be concluded that using UNB3m model gives tropospheric delay correction accuracy of $0.050 \mathrm{~m}$ in average for low latitude regions in all seasons. The model's accuracy is about $0.075 \mathrm{~m}$ for medium latitude regions, while its highest accuracy is about $0.014 \mathrm{~m}$ for high latitude regions.
\end{abstract}

Keywords: UNB3m model, Different latitude, Troposphere, IGS

\section{INTRODUCTION}

The most widely used formula for tropospheric refractivity $N$ is the (Smith and Weintraub, 1953) simplified two-term formula:

$$
N=77.6 \frac{P}{T}+3.73 \times 10^{5}\left(\frac{e}{T^{2}}\right)
$$


where,

$$
\begin{array}{lll}
P & : & \text { the total atmospheric pressure in (mbar), } \\
T & : & \text { temperature in Kelvin, } \\
e & : & \text { partial pressure of water vapour (mbar). }
\end{array}
$$

Three basic types of models exist that relate the parameters in equation (1.1) to either empirical Surface Meteorological (SM) measurements (surface meteorological models) or global standard atmospheres (global empirical models) or numerical weather predication models.

Surface Meteorological models are based on radiosonde profiles and relate the parameters of equation (1.1) to measurements taken at the ground surface. The most well known models are the Hopfield and Saastamoinen models (Farah, 2004). Global Empirical Models avoid the use of surface meteorological data and assume that the atmosphere behaves in a certain manner depending on the behaviour of the temperature, pressure, and humidity such as Bomford, Bernese, Magnet, EGNOS and UNB models. Global weather prediction models uses mathematical models of the atmosphere and oceans to predict the weather based on current weather conditions such as the North American Mesoscale Model (NAM), the Global Forecast System (GFS), and the long standing Nested Grid Model (NGM) (NCEI, 2015).

Several hybrid neutral atmosphere delay models have been developed by UNB researchers over the past decade or so. The most widely applicable current version is UNB3, which uses the Saastamoinen zenith delays, Niell mapping functions, and a look-up table with annual mean and amplitude for temperature, pressure, and water vapour pressure varying with respect to latitude and height. These parameters are computed for a particular latitude and day of year using a cosine function for the annual variation and a linear interpolation for latitude. The UNB3 model has been extensively used in several regions of the world, being capable of predicting total zenith delays with average uncertainties of $0.05 \mathrm{~m}$ under normal atmospheric conditions. UNB3m is a modified version of UNB3 has been used in GPS receivers utilizing the Wide Area Augmentation System and other space-based augmentation systems

This paper presents an assessment study for the UNB3m model. The zenith tropospheric estimations were compared from the model with IGS-estimates for three varying (latitude \& height) IGS stations (badg, masland nklg) (see Table 1.1). The tropospheric zenith delay data from four weeks in different seasons were chosen to assess the seasonal variation of the weather conditions (see Table 1.2). With the highly accurate estimation of the total tropospheric delay from the IGS-Tropospheric products, the differences of total zenith delay between the UNB3m model and the IGS-Troposphere estimation will give an indication of the quality of the model and assess its adequacy for tropospheric delay correction globally.

Table 1.1: The geographic positions of the tested IGS stations

\begin{tabular}{|l|l|c|l|}
\hline Station & $\begin{array}{l}\text { Latitude } \\
\text { (degrees) }\end{array}$ & $\begin{array}{l}\text { Longitude } \\
\text { (degrees) }\end{array}$ & $\begin{array}{l}\text { Orthometric Height } \\
\text { (metres) }\end{array}$ \\
\hline badg & $51.7697 \mathrm{~N}$ & $102.2350 \mathrm{E}$ & 850.250 \\
\hline mas1 & $27.7637 \mathrm{~N}$ & $15.6333 \mathrm{~W}$ & 155.494 \\
\hline nklg & $0.3539 \mathrm{~N}$ & $9.6721 \mathrm{E}$ & 21.477 \\
\hline
\end{tabular}


Table 1.2: The dates for (different-seasons) four weeks used in tropospheric delay mitigation study

\begin{tabular}{|c|c|c|c|c|}
\hline GPS week & 1814 & 1828 & 1840 & 1852 \\
\hline \multirow{2}{*}{ Date } & $12 / 10 / 2014-$ & $18 / 1 / 2015-$ & $12 / 4 / 2015-$ & $05 / 7 / 2015-$ \\
& $18 / 10 / 2014$ & $24 / 1 / 2015$ & $18 / 4 / 2015$ & $11 / 7 / 2015$ \\
\hline Season & Autumn & Winter & Spring & Summer \\
\hline
\end{tabular}

\section{UNB3M TROPOSPHERIC MODEL}

(Collins and Langley, 1997) proposed a hybrid neutral atmosphere model designed for Wide Area Augmentation System (WAAS) users. This model, called UNB3, has its algorithm based on the prediction of meteorological parameter values, which are then used to compute hydrostatic and non-hydrostatic zenith delays using the Saastamoinen models. The slant delays are determined using the Niell mapping functions. A modified version of UNB3 was actually adopted for WAAS with the Niell mapping functions being replaced by the single Black and Eisner mapping function and with some other minor simplifications (RTCA, 2001). The WAAS version of UNB3 has been favourably assessed for use with the European Geostationary Navigation Overlay Service (Dodson et al., 1999; Penna et al., 2001) and the Japanese Multifunctional Transport Satellite Augmentation System (Ueno et al., 2001). In order to account for the seasonal variation of the neutral atmosphere behaviour, a look-up table of meteorological parameters is used. The parameters are barometric pressure, temperature, water vapour pressure (WVP), temperature lapse rate ( $\beta$ ) and water vapour pressure height factor $(\lambda)$. This look-up table was derived from the U.S. Standard Atmosphere Supplements, 1966 (COESA, 1966). Table 2.1 shows the look-up table values for UNB3. The data is divided into two groups, to account for the annual average (mean) and amplitude of a cosine function for each parameter. Both amplitudes and averages vary with respect to latitude, for all parameters. The first step in the UNB3 algorithm is to obtain the meteorological parameter values for a particular latitude and day of year using the look-up table. By definition, the origin of the yearly variation is day of year (doy) 28. This procedure is similar to the one used in the Niell mapping functions computation. The interpolation between latitudes is done with a linear function. The annual average of a given parameter can be computed as: 
Table 2.1. Look-up table of UNB3 model

\begin{tabular}{|c|c|c|c|c|c|}
\hline \multicolumn{7}{|c|}{ Average } \\
\hline $\begin{array}{l}\text { Latitude } \\
\text { (degrees) }\end{array}$ & $\begin{array}{l}\text { Pressure } \\
\text { (mbar) }\end{array}$ & $\begin{array}{l}\text { Temperature } \\
(\mathbf{K})\end{array}$ & $\begin{array}{l}\mathbf{W V P}^{*} \\
(\mathbf{m b a r})\end{array}$ & $\boldsymbol{\beta}\left(\mathbf{K ~ m ~}^{-\mathbf{1}}\right)$ & $\lambda \mathbf{( - )}$ \\
\hline $\mathbf{1 5}$ & 1013.25 & 299.65 & 26.31 & $6.30 \mathrm{e}-3$ & 2.77 \\
\hline $\mathbf{3 0}$ & 1017.25 & 294.15 & 21.79 & $6.05 \mathrm{e}-3$ & 3.15 \\
\hline $\mathbf{4 5}$ & 1015.75 & 283.15 & 11.66 & $5.58 \mathrm{e}-3$ & 2.57 \\
\hline $\mathbf{6 0}$ & 1011.75 & 272.15 & 6.78 & $5.39 \mathrm{e}-3$ & 1.81 \\
\hline $\mathbf{7 5}$ & 1013.00 & 263.65 & 4.11 & $4.53 \mathrm{e}-3$ & 1.55 \\
\hline \multicolumn{7}{|c|}{ Amplitude } \\
\hline $\begin{array}{l}\text { Latitude } \\
\text { (degrees) }\end{array}$ & $\begin{array}{l}\text { Pressure } \\
\text { (mbar) }\end{array}$ & $\begin{array}{l}\text { Temperature } \\
\text { (K) }\end{array}$ & $\begin{array}{l}\text { WVP* } \\
(\mathbf{m b a r})\end{array}$ & $\boldsymbol{\beta}\left(\mathbf{K ~ m}^{-1}\right)$ & $\lambda \mathbf{( - )}$ \\
\hline $\mathbf{1 5}$ & 0.00 & 0.00 & 0.00 & 0.00 & 0.00 \\
\hline $\mathbf{3 0}$ & -3.75 & 7.00 & 8.85 & $0.25 \mathrm{e}-3$ & 0.33 \\
\hline $\mathbf{4 5}$ & -2.25 & 11.00 & 7.24 & $0.32 \mathrm{e}-3$ & 0.46 \\
\hline $\mathbf{6 0}$ & -1.75 & 15.00 & 5.36 & $0.81 \mathrm{e}-3$ & 0.74 \\
\hline $\mathbf{7 5}$ & -0.50 & 14.50 & 3.39 & $0.62 \mathrm{e}-3$ & 0.30 \\
\hline
\end{tabular}

$$
\operatorname{Avg}_{\phi}=\left\{\begin{array}{l}
\operatorname{Avg}_{15}, \text { if } \phi \leq 15 \\
\operatorname{Avg}_{75}, \text { if } \phi \geq 75 \\
\operatorname{Avg}_{\mathrm{i}}+\frac{\left(\mathrm{Avg}_{\mathrm{i}+1}-\mathrm{Avg}_{\mathrm{i}}\right)}{15} \cdot\left(\phi-\mathrm{Lat}_{\mathrm{i}}\right), \\
\quad \text { if } 15<\phi<75
\end{array}\right.
$$

where $\phi$ stands for the latitude of interest, in degrees, $\operatorname{Avg}_{\phi}$ is the computed average, $\mathrm{i}$ is the index of the nearest lower tabled latitude and Lat stands for latitude (from the table 2.1). The annual amplitude can be computed in a similar manner:

$$
A m p_{\phi}=\left\{\begin{array}{l}
A m p_{15}, \text { if } \phi \leq 15 \\
A m p_{75}, \text { if } \phi \geq 75 \\
A m p_{i}+\frac{\left(A m p_{i+1}-A m p_{i}\right)}{15} \cdot\left(\phi-L^{2} t_{i}\right), \\
\text { if } 15<\phi<75
\end{array}\right.
$$

where $\mathrm{Amp}_{\phi}$ stands for the computed amplitude. After average and amplitude are computed for given latitude, the parameter values can be estimated for the desired day of year according to:

$$
\mathrm{X}_{\phi, \text { doy }}=\mathrm{Avg}_{\phi}-\mathrm{Amp}_{\phi} \cdot \cos \left((\mathrm{doy}-28) \frac{2 \pi}{365.25}\right)
$$

where, $\mathrm{X}_{\phi \text {,doy }}$ represents the computed parameter value for latitude $\phi$ and day of year doy . This procedure is followed for each one of the five parameters. Once all five parameters are determined for given latitude and day of year, the zenith delays can be computed according to 


$$
\mathrm{d}_{\mathrm{h}}^{\mathrm{Z}}=\frac{10^{-6} \mathrm{k}_{1} \mathrm{R}}{\mathrm{gm}} \cdot \mathrm{P}_{0} \cdot\left(1-\frac{\beta \mathrm{H}}{\mathrm{T}_{0}}\right)^{\frac{\mathrm{g}}{\mathrm{R} \beta}}
$$

and

$$
d_{n h}^{Z}=\frac{10^{-6}\left(T_{m} k_{2}+k_{3}\right) R}{g_{m} \lambda^{\prime}-\beta R} \cdot \frac{e_{o}}{T_{o}} \cdot\left(1-\frac{\beta H}{T_{o}}\right)^{\frac{\lambda^{\prime} g}{R \beta}-1}
$$

Where,

- $\mathrm{T}_{\mathrm{o}}, \mathrm{P}_{\mathrm{o}}, \mathrm{e}_{\mathrm{o}}, \beta$, and $\lambda$ are the meteorological parameters computed according to (2.1) to (2.3);

- $\mathrm{H}$ is the orthometric height in $\mathrm{m}$;

- $\mathrm{R}$ is the gas constant for dry air $\left(287.054 \mathrm{~J} \mathrm{~kg}^{-1-} \mathrm{K}^{-1}\right)$;

- $\mathrm{g}_{\mathrm{m}}$ is the acceleration of gravity at the atmospheric column centroid in $\mathrm{m} \mathrm{s}^{-2}$ and can be computed from

$$
g_{m}=9.784\left(1-2.66 \times 10^{-3} \cos (2 \phi)-2.8 \times 10^{-7} \mathrm{H}\right)
$$

- $\mathrm{g}$ is the surface acceleration of gravity in $\mathrm{m} \mathrm{s}^{-2}$;

- $\mathrm{T}_{\mathrm{m}}$ is the mean temperature of water vapour in $\mathrm{K}$ and can be computed from

$$
\mathrm{T}_{\mathrm{m}}=\mathrm{T}\left(1-\frac{\beta \mathrm{R}}{\mathrm{g}_{\mathrm{m}} \lambda^{\prime}}\right)
$$

$\cdot \lambda^{\prime}=\lambda+1$ (unitless)

$\cdot \mathrm{k} 1, \mathrm{k} 2$ ' , and $\mathrm{k} 3$ are refractivity constants with values $77.60 \mathrm{~K} \mathrm{mbar}^{-1}, 16.6 \mathrm{~K} \mathrm{mbar}^{-1}$ and $377600 \mathrm{~K}^{2}$ mbar $^{-1}$, respectively.

The total slant delay can be finally computed according to

$$
d_{t}=m_{b} d_{h}^{z}+m_{n b} d_{n b}^{z}
$$

where $m_{h}$ and $m_{n h}$ stand for hydrostatic and nonhydrostatic (Niell, 1996) mapping functions, respectively. Further details about UNB3 development and performance can be found in (Collins and Langley, 1997). An extensive discussion of neutral atmosphere propagation delay modelling and testing can be found in (Mendes, 1999).

UNB3m was created by modifying parameter values in the UNB3 look-up table and the associated UNB3 algorithms. These changes were made in order to carry out the predictions using relative humidity rather than water vapour pressure. The part of the table that was related to water vapour pressure was replaced with values related to relative humidity. In UNB3m, all the computations for the point of interest are done initially using relative humidity, which is subsequently converted to water vapour pressure for use in the zenith delay computation. Further details about UNB3M development and performance can be found in (Leonardo et al., 2006). 


\section{ASSESSMENT STUDY}

\subsection{Low-Latitude Region}

The total tropospheric zenith delay estimates from UNB3m model and the IGS-Tropospheric delay estimates for (nklg) station (low latitude), for each of the four weeks are shown in Figures 1, 2, 3 and 4. Table 3.1.1 shows the total zenith delay difference analysis between the UNB3m model and the IGS-Tropospheric delay estimation for (nklg) station.



Fig. (1): Zenith tropospheric Correction for IGS station (nklg) from UNB3m model and IGS-Estimates during GPS week (1814) 


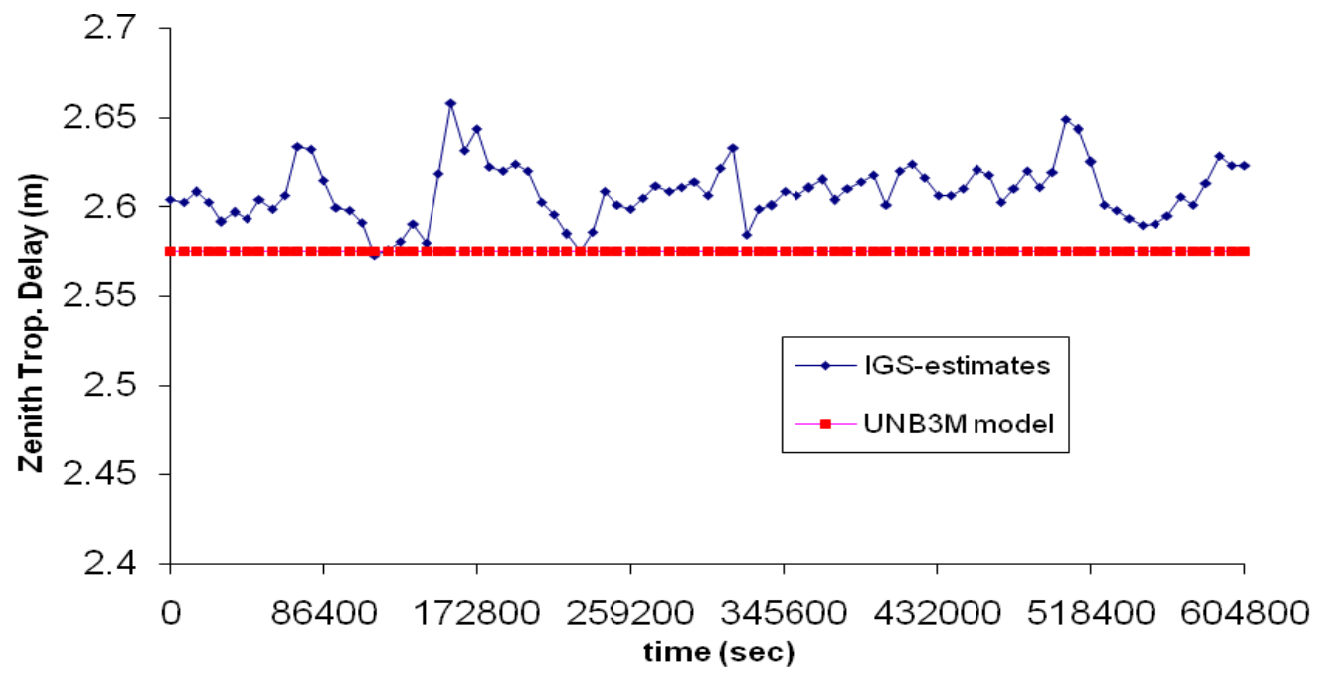

Fig. (2): Zenith tropospheric Correction for IGS station (nklg) from UNB3m model and IGS-Estimates during GPS week (1828)

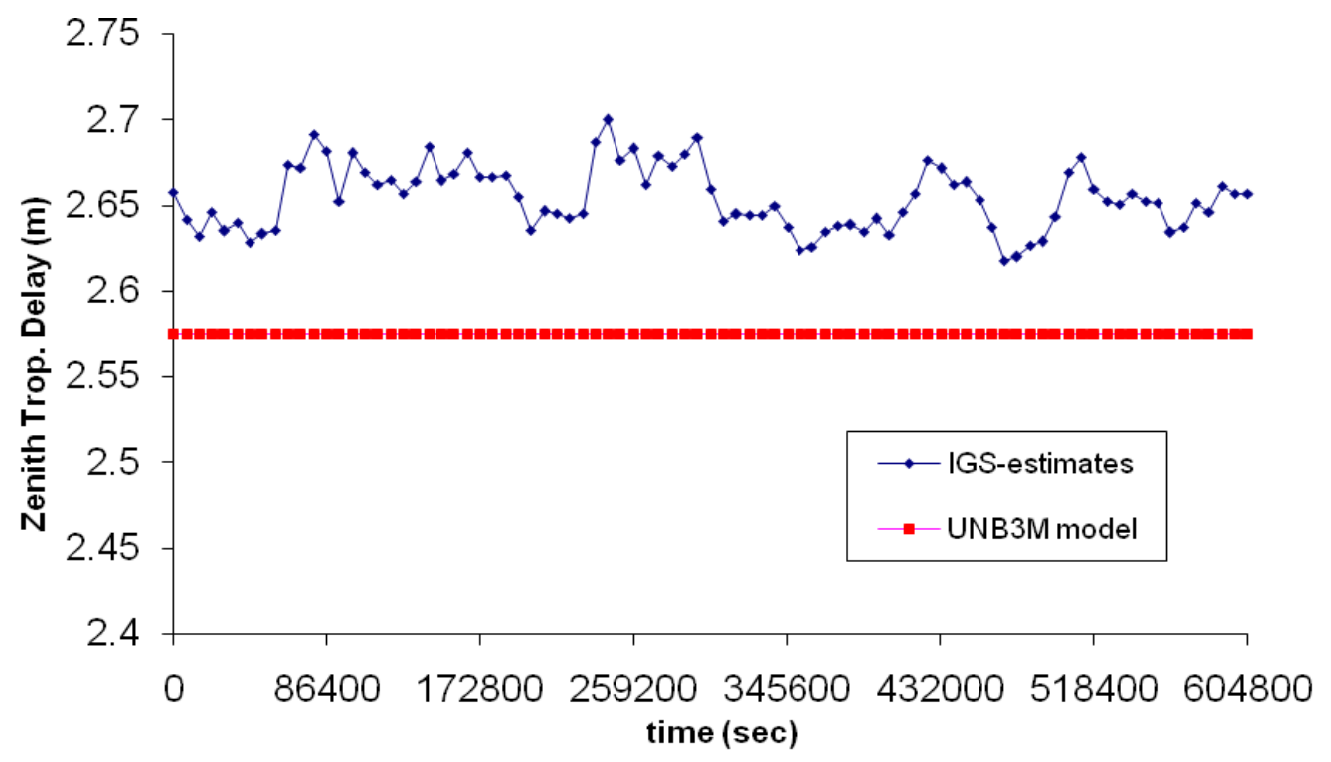

Fig. (3): Zenith tropospheric Correction for IGS station (nklg) from UNB3m model and IGS-Estimates during GPS week (1840) 


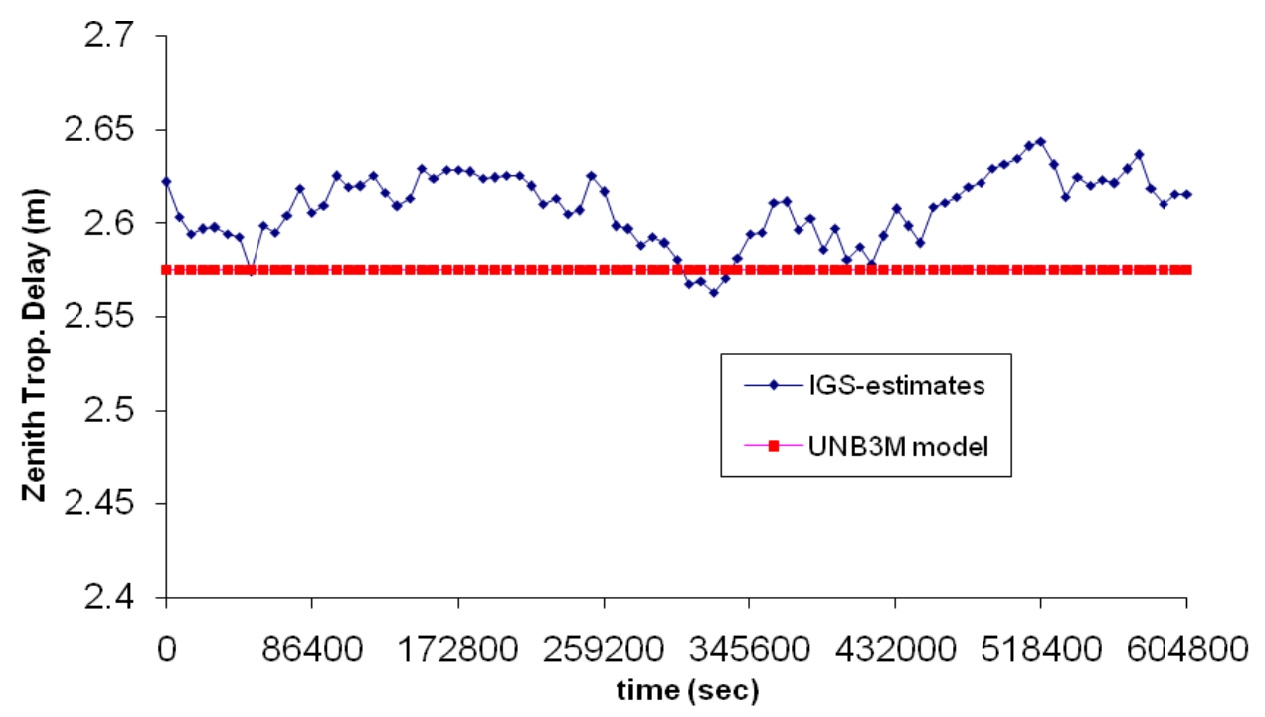

Fig. (4): Zenith tropospheric Correction for IGS station (nklg) from UNB3m model and IGS-Estimates during GPS week (1852)

Table 3.1.1: Total Tropospheric Zenith Delay Difference analysis between UNB3M Model and IGS-tropospheric estimation for (nklg- low latitude IGS station)

\begin{tabular}{|l|c|c|c|c|c|}
\hline \multirow{3}{*}{ Station } & GPS week & Min. (m) & Max. (m) & Mean (m) & RMS (m) \\
\hline \multirow{3}{*}{ Nklg } & 1814 & -0.1051 & -0.0384 & -0.0733 & 0.0154 \\
\cline { 2 - 6 } & 1828 & -0.0833 & 0.0022 & -0.0334 & 0.0163 \\
\cline { 2 - 6 } & 1840 & -0.1248 & -0.0427 & -0.0794 & 0.0184 \\
\cline { 2 - 6 } & 1852 & -0.0686 & 0.0120 & -0.0333 & 0.0180 \\
\hline
\end{tabular}

\subsection{Medium-Latitude Region}

The total tropospheric zenith delay estimates from UNB3m model and the IGS-Tropospheric delay estimates for (mas1) station (med. latitude), for each of the four weeks are shown in Figures 5, 6, 7 and 8. Table 3.2.1 shows the total zenith delay difference analysis between the UNB3m model and the IGS-Tropospheric delay estimation for (mas1) station. 


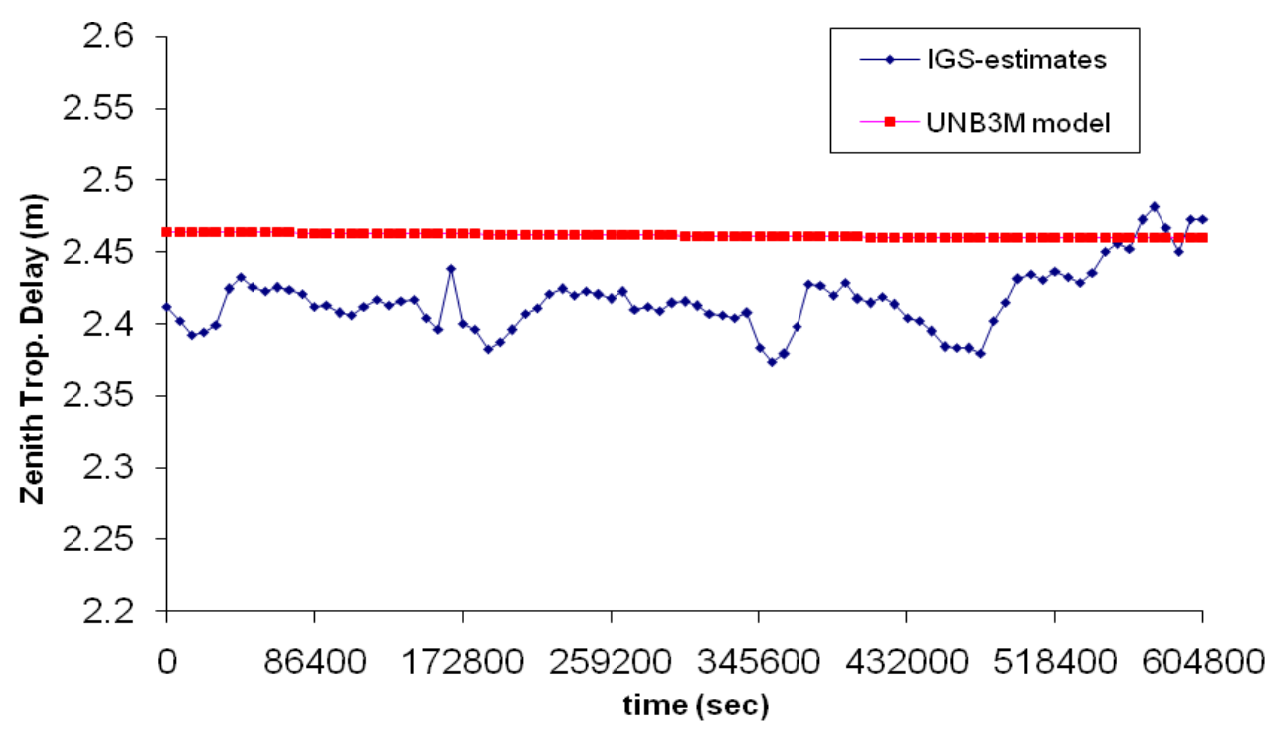

Fig. (5): Zenith tropospheric Correction for IGS station (mas1) from UNB3m model and IGS-Estimates during GPS week (1814)

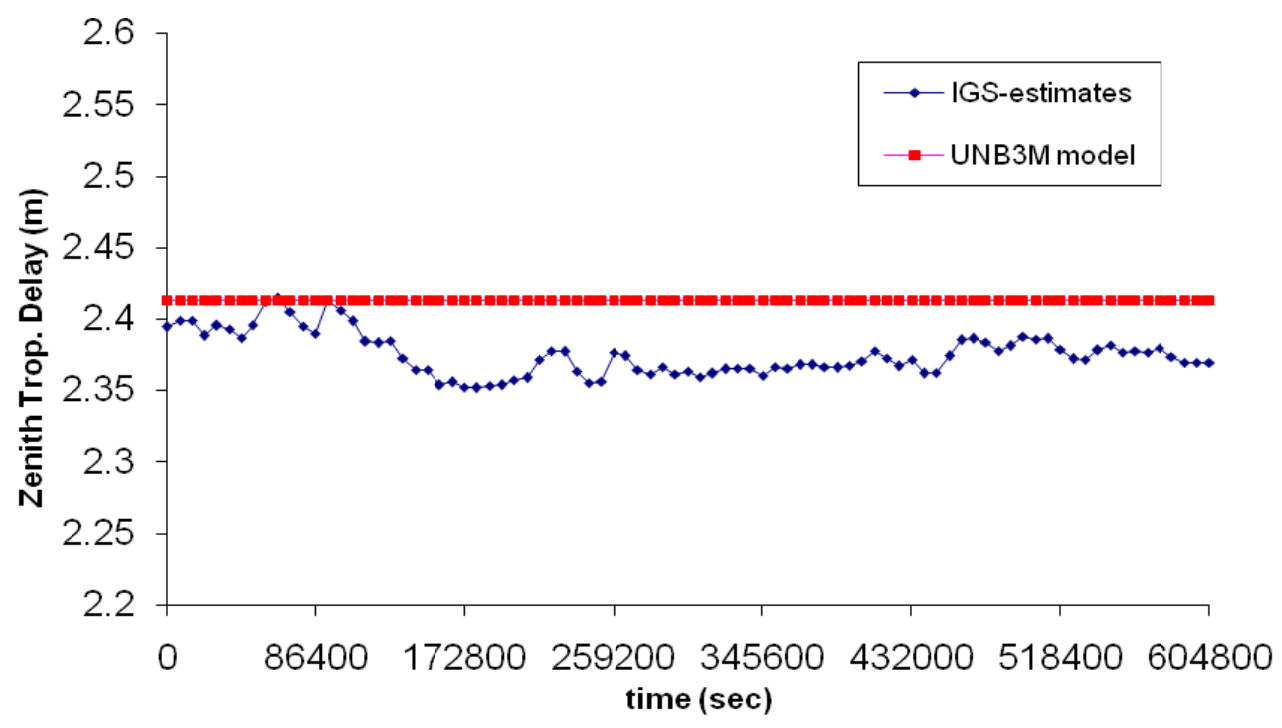

Fig. (6): Zenith tropospheric Correction for IGS station (mas1) from UNB3m model and IGS-Estimates during GPS week (1828) 


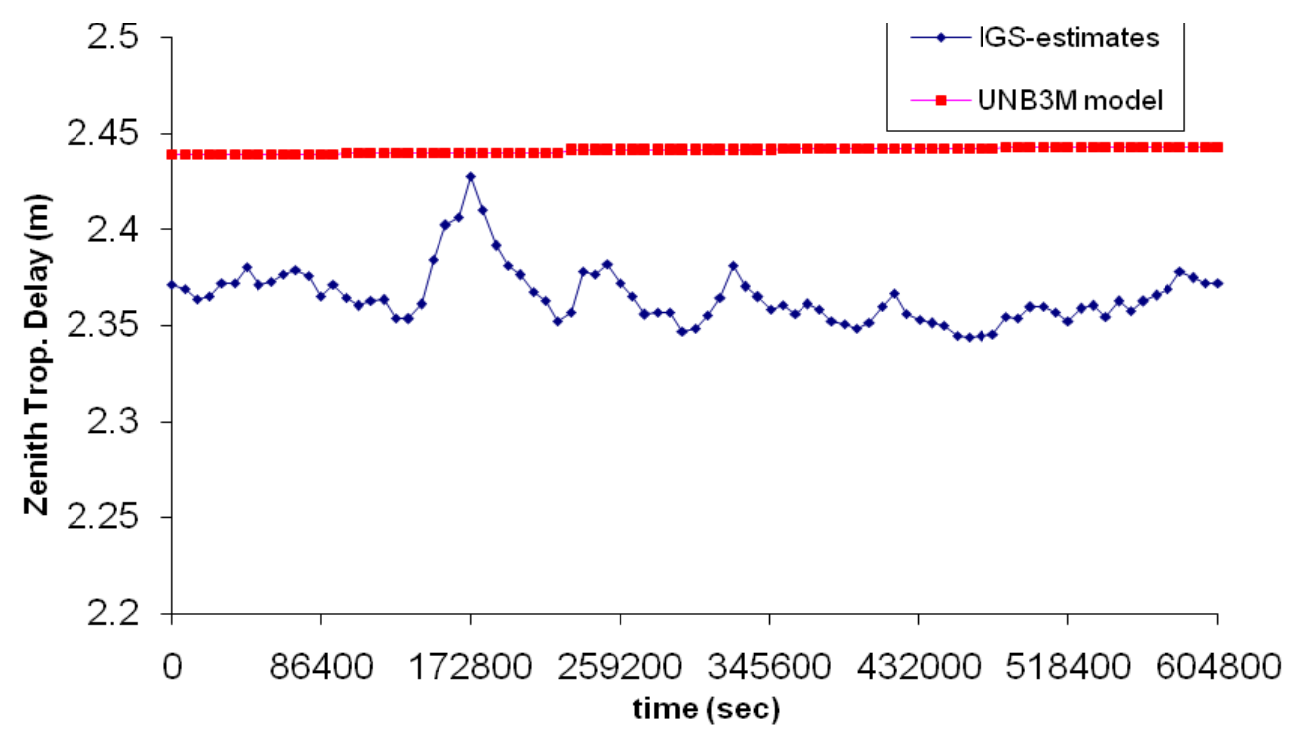

Fig. (7): Zenith tropospheric Correction for IGS station (mas1) from UNB3m model and IGS-Estimates during GPS week (1840)



Fig. (8): Zenith tropospheric Correction for IGS station (mas1) from UNB3m model and IGS-Estimates during GPS week (1852) 
Table 3.2.1: Total Tropospheric Zenith Delay Difference analysis between UNB3M Model and IGS-tropospheric estimation for (mas1-medium latitude IGS station)

\begin{tabular}{|l|c|c|c|c|c|}
\hline \multirow{3}{*}{ Station } & GPS week & Min. (m) & Max. (m) & Mean (m) & RMS (m) \\
\hline \multirow{4}{*}{ mas1 } & 1814 & -0.0214 & 0.0877 & 0.0449 & 0.0225 \\
\cline { 2 - 6 } & 1828 & -0.0019 & 0.0613 & 0.0378 & 0.0148 \\
\cline { 2 - 6 } & 1840 & 0.0125 & 0.0982 & 0.0757 & 0.0153 \\
\cline { 2 - 6 } & 1852 & 0.0246 & 0.1547 & 0.1117 & 0.0284 \\
\hline
\end{tabular}

\subsection{High-Latitude Region}

The total tropospheric zenith delay estimates from UNB3m model and the IGS-Tropospheric delay estimates for (badg) station (high latitude), for each of the four weeks are shown in Figures 9, 10, 11 and 12. Table 3.3.1 shows the total zenith delay differences analysis between the UNB3m model and the IGS-Tropospheric delay estimation for (badg) station. Note that some of the IGS estimation in Figure 10 contains null periods due to a lack of data.



Fig. (9): Zenith tropospheric Correction for IGS station (badg) from UNB3m model and IGS-Estimates during GPS week (1814) 


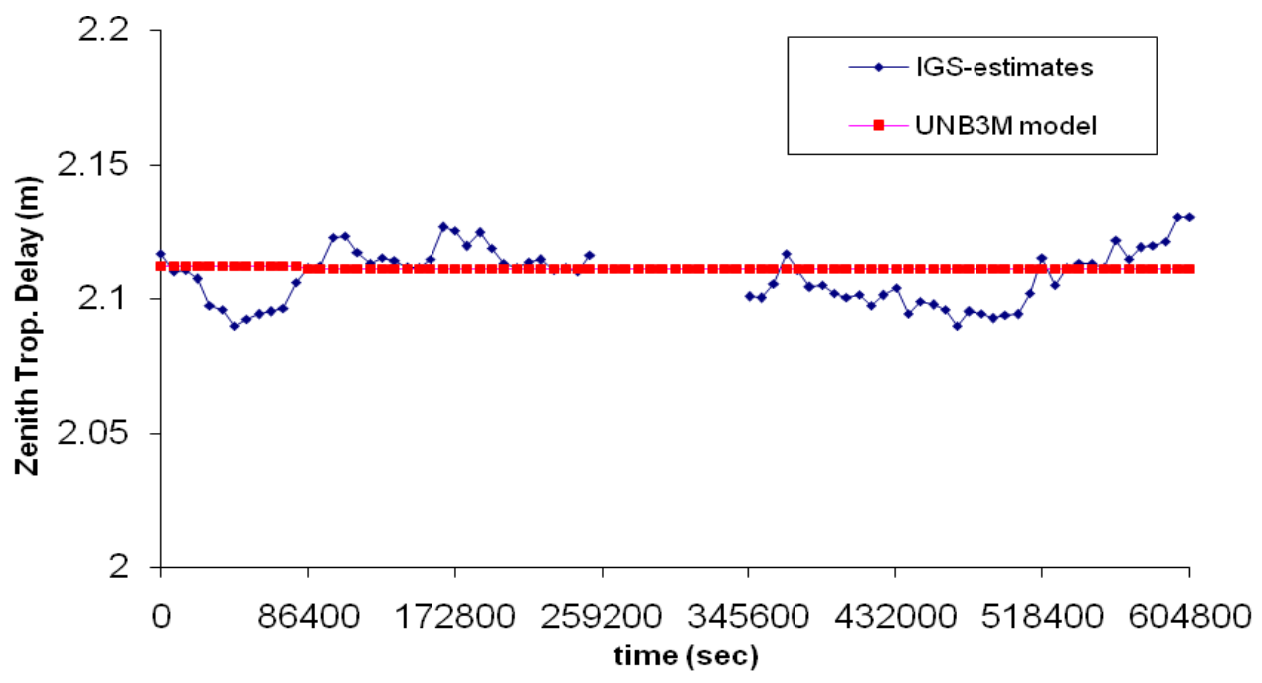

Fig. (10): Zenith tropospheric Correction for IGS station (badg) from UNB3m model and IGS-Estimates during GPS week (1828)

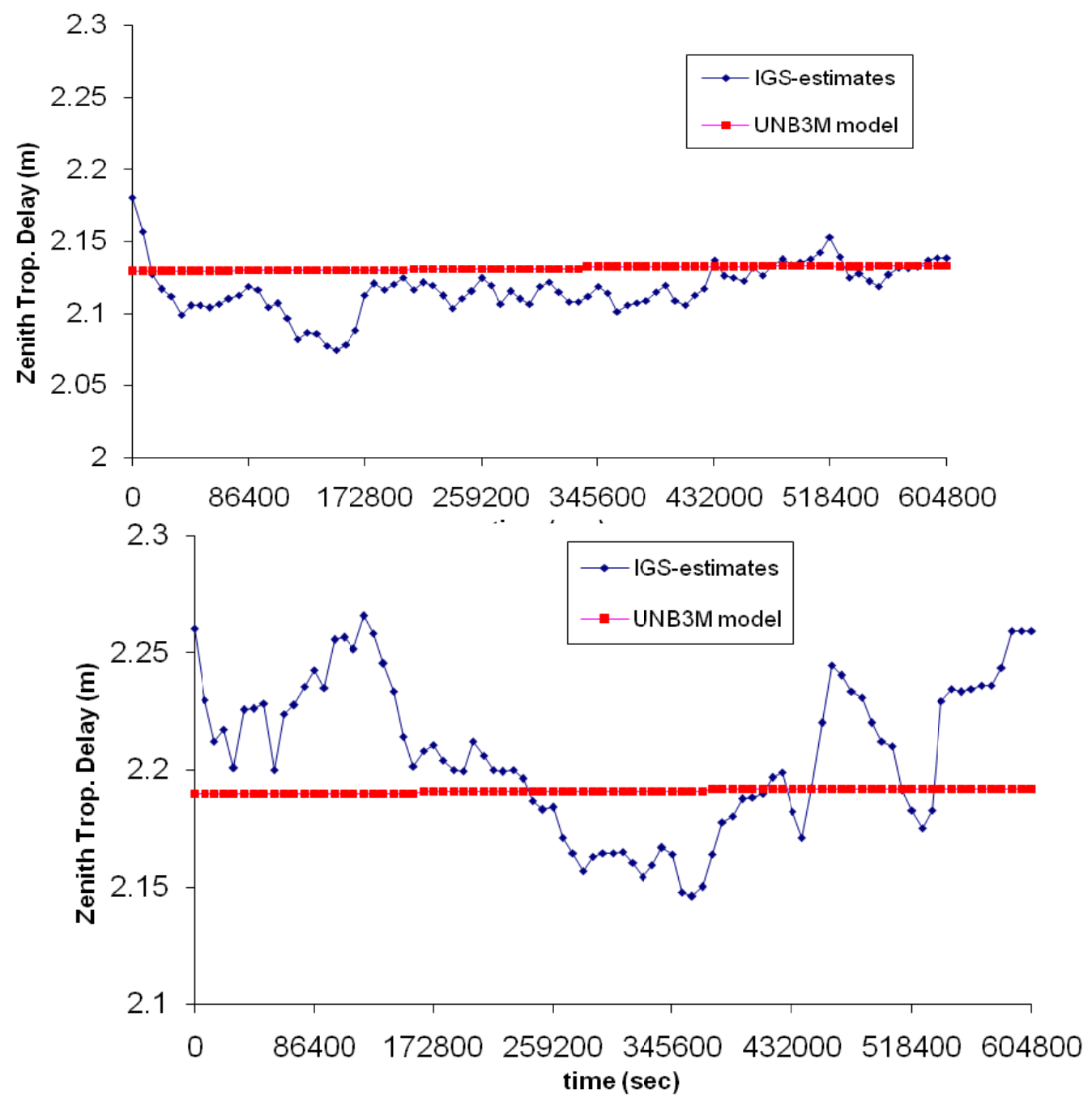

Fig. (12): Zenith tropospheric Correction for IGS station (badg) from UNB3m model and IGS-Estimates during 
Table

3.3.1: Total Tropospheric Zenith Delay Difference analysis between UNB3M Model and IGStropospheric estimation for (badg-high latitude IGS station)

\begin{tabular}{|l|c|c|c|c|c|}
\hline \multirow{3}{*}{ Station } & GPS week & Min. (m) & Max. (m) & Mean (m) & RMS (m) \\
\hline \multirow{4}{*}{ badg } & 1814 & 0.0105 & 0.0419 & 0.0240 & 0.0072 \\
\cline { 2 - 6 } & 1828 & -0.0195 & 0.022 & 0.0026 & 0.0112 \\
\cline { 2 - 6 } & 1840 & -0.0513 & 0.0555 & 0.0139 & 0.0167 \\
\cline { 2 - 6 } & 1852 & -0.0758 & 0.0451 & -0.0152 & 0.0322 \\
\hline
\end{tabular}

\section{DISCUSSION}

From the above shown figures ( 1 to 4$) \&$ table 3.1 .1 for low latitude region, it is shown that the UNB3m model is giving better behavior in winter and summer seasons comparing with its behavior in autumn and spring seasons. The average mean difference between the model and IGS estimates is about $0.030 \mathrm{~m}$ in winter and summer seasons. While the average mean difference between the model and IGS estimates is about $0.070 \mathrm{~m}$ in autumn and spring seasons.

From the above shown figures (5 to 8) \& table 3.2.1 for medium latitude region, it is shown that the UNB3m model is following closely IGS estimates in winter and autumn seasons rather than summer and spring seasons. The model is giving its best behavior in winter season with average mean difference of about $0.030 \mathrm{~m}$ while the average mean difference is about $0.040 \mathrm{~m}$ in autumn season. While, the average mean difference between the model and IGS estimates is about $0.070 \mathrm{~m}$ in spring season. The model is shown its worst behavior in summer season with an average mean difference of $0.110 \mathrm{~m}$.

From the above shown figures ( 9 to 12 ) \& table 3.3.1 for high latitude region, it is shown that the UNB3m model is following closely the IGS estimates in winter, spring and summer seasons better than autumn season. The average mean differences are $0.003 \mathrm{~m}, 0.013 \mathrm{~m}$ and $0.015 \mathrm{~m}$ in winter, spring and summer seasons respectively. While the average mean difference is $0.024 \mathrm{~m}$ in autumn season.

It can concluded in general that the UNB3m model is giving better behavior for high latitude regions rather than medium and low latitude regions. This could be explained by the fact that the 
model look up table (table 2.1) for atmospheric parameters was derived from the U.S. Standard Atmosphere Supplements, 1966 (COESA, 1966).

\section{CONCLUSIONS}

It is recommended to use UNB3M model for estimating the zenith trop. delay correction for low latitude regions in seasons; winter and summer. For medium latitude regions, the model is behaving better in winter and autumn seasons, while it is recommended to use the model for trop. delay correction in winter and spring seasons.

UNB3m model gives tropospheric delay correction accuracy of $0.050 \mathrm{~m}$ in average for low latitude regions in all seasons. The model's accuracy is about $0.075 \mathrm{~m}$ for medium latitude regions, while its highest accuracy is about $0.014 \mathrm{~m}$ for high latitude regions.

\section{REFERENCES}

COESA (1966). U.S. Standard Atmosphere Supplements, 1966. U.S. Committee on Extension to the Standard Atmosphere. Sponsored by Environmental Science Services Administration, National Aeronautics and Space Administration, United States Air Force and published by the Superintendent of Documents, U.S. Government Printing Office, Washington, D.C.

Collins, J.P. and R.B. Langely (1997). A Tropospheric Delay Model for the User of the Wide Area Augmentation System. Final contract report prepared for Nav Canada, Department of Geodesy and Geomatics Engineering Technical Report No. 187, University of New Brunswick, Federiction, N.B., Canada.

Collins, J.P. and R.B. Langely (1998). The residual tropospheric propagation delay: How bad can it get? Proceeding of ION GPS-98, The $11^{\text {th }}$ International Meeting of the Satellite Division of The Institute of Navigation, Nashville, Tenn., September 15-18, pp. 729-738.

Dodson, A.H. W. Chen, H.C. Baker, N.T. Penna, G.W. Roberts, J. Westbrook, and R. Jeans (1999). Assessment of EGNOS Tropospheric Correction Model. Proceeding of ION GPS-99, The $12^{\text {th }}$ International Meeting of the Satellite Division of The Institute of Navigation, Nashville, Tenn., September 14-17, pp. 1401-1407.

Farah, A. (2004). GPS/GALILEO Simulation for Reduced Dynamic LEO Satellite Orbit Determination. PhD thesis. Nottingham University. UK.

Leonardo, R., Marcelo Santos, and Richard B. Langley (2006)." UNB Neutral Atmosphere Models: Development and Performance". ION, national technical meeting, 2006.

Mendes, V. B. (1999). Modeling the Neutral-Atmosphere Propagation Delay in Radiometric Space Techniques. Ph.D. dissertation, Department of Geodesy and Geomatics Engineering Technical Report No. 199, University of New Brunswick, Fredericton, New Brunswick, Canada, pp. 353.

NCEI (2015). Numerical weather prediction, National Centers for Environmental Information (NCEI), (https://www.ncdc.noaa.gov/data-access/model-data/model-datasets/numericalweather-prediction) (Accessed 1/9/2015).

Niell, A.E. (1996) Global Mapping Functions for the Atmospheric Delay at Radio Wavelengths, Journal of Geophysical Research, Vol 101, No B2, pp. 3227-3246, 10 February 1996. 
Penna, N., A. Dodson, and W. Chen, (2001) Assessment of EGNOS Tropospheric Correction Model. Journal of Navigation, Vol. 54, Issue 1, pp. 37-55.

RTCA (1999). Minimum operational performance standards for Global Positioning System/ Wide Area Augmentation System airborne equipment. RTCA DO-229B, Issue 10 June 1999.

RTCA, Inc. (2001) DO-229C, Minimum Operational Performance Standards for Global Positioning

System/Wide Area Augmentation System Airborne Equipment, SC-169, RTCA, Inc., Washington, D.C.

Saastamoinen, J. (1973) Contributions to the Theory of Atmospheric Refraction. Part II Refraction Corrections in Satellite Geodesy. Bulletin Geodesique, pp. 13-34.

Smith, E. K. and Weintraub, S. (1953) The Constants in the Equation for The Atmospheric Refractive Index at Radio Frequencies. In: Proceeding of the Inst. Of Radio Engineers, 41, pp. 1035-1057.

Ueno, M., K. Hoshinoo, K. Matsunaga, M. Kawai, H. Nakao, and R.B. Langley, (2001). "Assessment of Atmospheric Delay Correction Models for the Japanese MSAS." Proceedings of ION GPS 2001, 14 ${ }^{\text {th }}$ International Technical Meeting of the Satellite Division of The Institute of Navigation, Salt Lake City, UT, 11-14 September 2001, pp. 2341-2350.

Received: 2015-08-24,

Reviewed: 2015-10-14,

Accepted: 2015-10-19. 